\title{
The moral disengagement mechanisms in organizational contexts: A comparison between public organizations and private firms
}

\author{
Maurizio Zorzetto \\ Local Police Chief Commissioner in Bernareggio e Aicurzio, Lombardy, graduated in December 2017 from the University \\ of Rome, Unitelma Sapienza with a degree in Management and Security and a thesis in Social Psychology, Italy
}

\begin{abstract}
The moral disengagement present in work places is a critical factor impacting the efficient pursuit of organizational goals. This research aims at providing a new view on the criticisms moved against the inefficiencies of the Italian public administration and the national bureaucratic system, by adopting the principles described in Albert Bandura's (1986) Social Cognitive theory and testing the mechanisms of moral disengagement empirically, by carrying out the Civic Moral Disengagement (CMD) survey among private and public-sector employees. The final goal of this research is analyzing the cognitive process that employees activate based on the environment they are in, and defining an Empowerment strategy that could be adopted within public organizations.
\end{abstract}

\section{RIASSUNTO}

Il disimpegno morale che caratterizza i contesti lavorativi, rappresenta l'elemento critico che condiziona l'efficace perseguimento degli obiettivi di un'organizzazione. Abbracciando i principi descritti nella teoria social cognitiva proposta da Albert Bandura (1986) e sperimentando empiricamente i meccanismi di disimpegno morale attraverso la somministrazione del questionario del disimpegno morale civile ad un campione di lavoratori pubblici e di lavoratori privati, si propone con questa ricerca una nuova chiave di lettura alle critiche mosse rispetto il buon andamento della pubblica amministrazione italiana ed alle inefficienze dell'apparato burocratico nazionale, finalizzata all'analisi dei processi cognitivi attivati dal lavoratore in funzione dell'ambiente in cui si inserisce ed alla definizione di strategie di empowerment applicabili alla pubblica amministrazione.

\section{RESUMEN}

La desvinculación moral que caracteriza el ambiente de trabajo, representa el elemento crítico que condiciona el efectivo logro de los objetivos de una organización. Abrazando los principios que figuran en la teoría cognitiva social de Albert Bandura (1986) y experimentando concretamente los mecanismos de desvinculación moral a través del cuestionario de desconexión moral civil hecho por una muestra de trabajadores públicos y trabajadores privados, se quiere propeoner una nueva visión de las críticas sobre el funcionamiento del la administración pública italiana y sobre las ineficiencias de el aparato burocrático nacional, con el fin de analizar los procesos cognitivos activados por el trabajador en función del ambiente en el que se inserta y a la definición de estrategias de empowerment aplicables a la administración pública.

\section{Introduction}

The question is whether the criticism put forward towards the public administration, and in particular the inefficiency of the Italian bureaucratic system, can be attributed to a mere stereotype built on a categorization originating from simplistic labelling of public sector employees (see the Theory of Social Identity, Tajfel 1974), or whether factual causes of psychological nature can explain the behavioral differences between public and private sector employees.

To answer this question, it is necessary to adopt the theoretical approaches suggested by Social Psychology and Sociology on deviance. This implies assuming that the attitude and conduct commonly associated with public employees can be considered deviance, defined as actions and behaviors that violate social norms either from a legal standpoint of from an ethical one. Social norms are commonly accepted across society and learned by individuals through primary and secondary socialization processes. They constitute a moral self-regulatory system, defining the framework within which actions are approved by the group to which individuals belong, to which they conform and within which they seek acceptance. The violation of commonly shared social norms inevitably activates punishment, which can either be internal or external, formal or informal and which, following the Theory of Social Control (Hirschi), constitutes the real deterrent deviances.

Albert Bandura's Social Cognitive Theory plays a prominent role among the different theories that try to explain both the origins and the consequences of deviances. According to this theory, individual behaviors are determined by the social environment, considered not only as the physical and geographical environment, but also as the place where social relations take place. Particular attention has been given to the concept of moral disengagement, described by Bandura as comprised by the eight mechanisms of moral disengagement, that were later extended into twelve mechanisms by Professor Vincenzo Mastronardi. Those mechanisms, when activated by individuals, allow to overcome the limits and norms imposed by their self-regulatory system. Some mechanisms anticipate the deviant behavior, strengthening individual's intention, in line with the Theory of Reasoned Action (Ajzen) and even more with the concept proposed by Ajzen in the Theory of Planned Behavior, according to which behavioral 
intention is a function of both attitudes and subjective norms towards that behavior. Some other mechanisms are adopted subsequently to the deviant behavior and act as justifications, thus providing relief to the feeling of guilt and self-blame, deriving from the awareness of having violated group's social norms.

The aforementioned mechanisms were applied to a research on aggressiveness during adolescence by Caprera and Bandura in 1996, leading to the definition of a moral disengagement scale measured through a survey composed of 32 items. Only in 2006, in a study by Caprera, Barbaranelli, Pastorelli, Iafrate, Steco, Brambilla and Bandura, involving the universities of Roma Sapienza, Milano Bicocca and Stanford University, the model was applied to disengagement in everyday life, with the definition of a Civic Moral Disengagement scale, through the definition of a new survey, consisting of 40 items, divided into 5 blocks and related to the eight mechanisms of Civic Moral Disengagement. The questionnaire has been empirically tested and validated with Cronbach's Aplha method, which recognizes scientifically validity for the measurement of behaviors in everyday life context, such as family life, work life and any other environment in which individuals act.

Once chosen the survey tool developed by Caprera et al. (2006) as suitable for the study, the research moved on analyzing the variances in the mechanisms of moral disengagement adopted by different categories of employees, so to define the potential differences in cognitive processes and evaluate the influence of the environment on the adoption of specific behaviors.

\section{Empirical research}

Even though the survey tool is known and validated, the lack of specific studies on this phenomenon required a detailed research planning, aimed at defining the knowledge framework, the statistical relations to be analyzed and the research strategies to adopt.

The knowledge framework is characterized by unknown sources and not available data, for which reason, it was deemed necessary to collect as much data and information as possible to allow the elaboration of results and interpret the phenomenon. The research has followed the correspondence analysis method developed by the French Social Statistics school and described by Banzecrì (1992). Differently from the original study on Civic Moral Disengagement, the analysis compares the distribution of values collected among public and private sector employees, both looking at the overall data from the two sectors, and dividing data by gender.

Because of the structure of the questionnaire, which asks respondents to select a value between 1 and 5 for each statements, with 1 representing complete disapproval and 5 representing complete approval, data elaboration does not allow calculating a simple mean, but rather makes it necessary to evaluate a distribution defining a trend line associated to correlation.

In relation to the chosen correspondence analysis method, as defined in the study's knowledge framework, the values resulting from the research could be used in the analysis and possibly assume the value of social indicators. The following statistical data will be considered relevant for the analysis:

$\mathrm{F}=$ number of female respondents;

$\mathrm{PrF}=$ number of female respondents in the private sector; $\mathrm{PbF}=$ number of female respondents in the public sector; $\mathrm{M}=$ number of male respondents;

$\mathrm{PrM}=$ number of male respondents in the private sector; $\mathrm{PbM}=$ number of male respondents in the public sector; $\mathrm{Pr}=$ number of respondents in the private sector; $\mathrm{Pb}=$ number of respondents in the public sector;
CMD (x) pr(i)=Number or the answers for each ranking of a single item $(\mathrm{x})$, where $\mathrm{x}$ is the identification number of the item, while (I) is the value from 1 to 5 in the private sector;

$\mathrm{CMD}(\mathrm{x}) \mathrm{pb}(\mathrm{i})=$ Number or the answers for each ranking of a single item, where (x) is the identification number of the item, while (I) is the value from 1 to 5 in the public sector;

CMD (x) Fpr(i)=Number or the aswers for each ranking of a single item (x), where $\mathrm{x}$ is the identification number of the item, while (I) is the value from 1 to 5 for female employees in the private sector; $\mathrm{CMD}(\mathrm{x}) \mathrm{Fpb}(\mathrm{i})=$ Number or the answers for each ranking of a single item, where (x) is the identification number of the item, while (I) is the value from 1 to 5 for female employees in the public sector; CMD (x) Mpr(i)=Number or the aswers for each ranking of a single item (x), where $\mathrm{x}$ is the identification number of the item, while (I) is the value from 1 to 5 for male employees in the private sector; CMD (x) $\mathrm{Mpb}(\mathrm{i})=$ Number or the answers for each ranking of a single item, where (x) is the identification number of the item, while (I) is the value from 1 to 5 for male employees in the public sector.

\section{Coefficients}

The values resulting from the application of the least square method to the two different selected samples, both in the overall view $(\mathrm{Pb}-$ public sector respondents and $\mathrm{Pr}-$ private sector respondents) and in the gender stratification $(\mathrm{PbF}, \mathrm{PrF}, \mathrm{PbM}$, and PrM) are adopted as coefficients for the comparative analysis.

Similarly to the pilot research (Caprara, 2006), this study presents the value of squared correlation $\left(\mathrm{r}^{2}\right)$, derived from the dispersion graphics built for each item with Excel.

While analyzing the distribution of coefficients by gender, it has emerged that some questionnaire respondents did not express their gender, thus determining an involuntary third sample stratification, which could not be integrated to any of the other stratifications, and had to be analyzed separately. Even though this third sample stratification, identified as $\mathrm{PbN}$ and $\mathrm{PrN}$, is not significant, it had to be distinguished from the other gender coefficients and excluded in the comparison analysis between gender distributions. In the overall analysis, instead, these values have been taken into consideration and summed to the remaining gender differentiated data, so to study the whole sample.

Once the values for each item have been determined and analyzed, also distinguishing results by gender, it has been decided that the comparison between the two samples had to be based on the squared correlation determined on the overall value for each moral disengagement mechanism. The comparison of single items, indeed, is not representative for the use of a specific mechanism. For this reason, the chosen model comprises the ideal number of items, as defined by Caprera et al. (2006).

The overall correlation among different items related to one moral disengagement mechanisms, will not be determined as a simple arithmetic mean, but rather applying the least square method to the overall distribution of the answers to the 5 items related to one of the eight moral disengagement mechanisms.

In conclusion, the study will assess the coefficients previously defined relative to the various moral disengagement mechanisms, applying the square of the correlation formula, both to the overall sample from public and private employees, and to the gender stratification.

While defining the samples, which will be drawn from two populations (i.e. private firms and public organization employees), stratification techniques will have to be adopted, to assure 
comparability across data gathered from the statistical units (employees).

Being the study based on a sample survey, the comparison will focus on the analysis of the previously defined coefficients characterizing the two samples and on the sample stratifications, defined through the subsidiary elements gathered for each statistical unit (i.e. age group, gender, work category). In addition to the statistical units' subsidiary elements, the research will have to take into consideration also the features of the organizations in which responses are gathered. Indeed, even though the selected private and public organizations do not constitute the focus of the study per se, they are the main element impacting the environmental and social conditions surrounding employees, which in turn play a key role in the theoretical framework of the study.

For instance, the impact on employees' social cognitive processes produced by a large, highly-structured and unionized private organization, with a high degree of occupational, cultural, social and ethnic variety may greatly differ from the influence on cognitive processes that a small artisanal business, where relationships between employer and employee are close and informal, can have on employees. These differences could generate a high level of variety among statistical units belonging to the same organization and would make the comparison with public organizations hard to manage.

To allow data comparability, it will be necessary to select statistical units applying a stratification method to the survey units. The study has selected public administrations whose workforce does not exceed 100 resources, and private companies whose organic that does not exceed 300 employees. In this way, data on public administrations' employees is comparable to that of private firms' employees. On the other hand, the research will exclude private organizations whose workforce consists of only few resources, for previously specified reasons. This selection will not be necessary in the public sector, where rigid organizational structures and hierarchies, also linked to the provisional nature of elective public roles, persist also in small contexts.

The adopted sampling strategy consists in defining two population groups: municipalities' employees and private companies' employees. Samples will be drawn from both populations within the provinces of Monza and Lecco, with the aforementioned stratified sampling technique based on the organizations' number of employees. After having selected the two samples, the questionnaire will be provided to the single statistical units: the organizations' employees.

Before distributing the questionnaire, measures had to be taken to assure the complete anonymity of the survey. Indeed, it must be noted that employees could doubt that the research questionnaire, enquiring on moral disengagement, could be distributed from their supervisors, thus causing a major invasion of their privacy. For this reason, guaranteeing the absolute protection of respondents' identity is key to obtaining an adequate participation, which, in turn, is crucial for the success of the research.

Questionnaire items will be managed through a rating scale, while subsidiary information on respondents will be gathered though an input form, requesting information according to the following predefined categories:

- Gender: Male or Female

- Age: 18-25, 26-40, 41-55, 56 and over

- Work area: Public or private sector

- Category in the public sector: A-B, C-D, PO, Manager

- Category in the private sector: worker, employee, manager and executive

Besides being the questionnaire anonymous and participation voluntary, further precautions based on psychological elements have been considered necessary to reassure respondents of a higher protection of their privacy. Questionnaires were distributed directly by the researcher after having briefly explained the research aim and the methods granting response anonymity.

Some respondents filled the questionnaire in front of the researcher, others did it on their own, while some others answered the items in groups and handed them in sealed envelope and were reassured that the opening of those envelops would occur once all the questionnaires had been gathered.

While defining the sample, it has been deemed necessary to include public and private organizations with comparable size: medium sized private firms (i.e. firms with less than 300 employees) and local public services with less than 100 employees and serving no more than 20.000 inhabitants.

A total of six organizations within the public sector have been selected, all of which are municipalities in the province of Monza and Brianza and Lecco. Out of a total of 155 employees, 67 took part to the survey, of which 42 women, 17 men and 8 respondents who preferred not to express their gender. All employees covered different roles.

A total of 7 middle sized private firms within the same geographical area have been involved. 58 employees out 145 answered the questionnaire, 13 women and 45 men, with various roles.

The distribution of male and female genders within the two samples shows a majority of women in the public sector, while the male gender has prevailed in the private sector (Figure 1). This was due to manufacturing nature of the private companies involved.

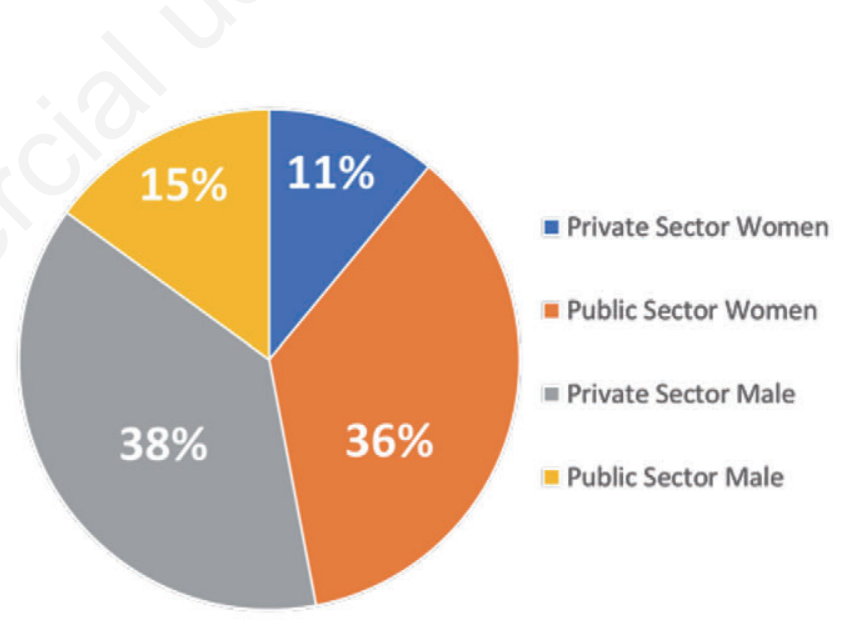

Figure 1. Gender distribution within the sample.

By applying the least square method to the distributions, the following coefficients have resulted in relation to the questionnaire items:

\begin{tabular}{lllllll} 
& PbF & PbM & PrF & PrM & Pbn & Prn \\
CMD1 & 0.505 & 0.547 & 0.562 & 0.577 & 0.605 & 0.125 \\
CMD2 & 0.668 & 0.472 & 0.821 & 0.527 & 0.797 & 0.125 \\
\hline CMD3 & 0.350 & 0.009 & 0.083 & 0.621 & 0.019 & 0.500 \\
CMD4 & 0.853 & 0.786 & 0.434 & 0.853 & 0.145 & 0.083 \\
\hline CMD5 & 0.649 & 0.472 & 0.333 & 0.596 & 0.285 & 0.781 \\
CMD6 & 0.518 & 0.445 & 0.771 & 0.777 & 0.125 & 0.500 \\
\hline CMD7 & 0.605 & 0.685 & 0.669 & 0.570 & 0.272 & 0.083 \\
\hline
\end{tabular}




\begin{tabular}{lllllll} 
CMD8 & 0.598 & 0.621 & 0.349 & 0.717 & 0.321 & 0.750 \\
\hline CMD9 & 0.707 & 0.209 & 0.125 & 0,876 & 0,125 & 0,000 \\
CMD10 & 0,782 & 0,721 & 0,821 & 0,758 & 0,614 & 0,500 \\
\hline CMD11 & 0,764 & 0,771 & 0,333 & 0,633 & 0,750 & 0,083 \\
CMD12 & 0,660 & 0,568 & 0,631 & 0,900 & 0,285 & 0,781 \\
\hline CMD13 & 0,980 & 0,832 & 0,571 & 0,699 & 0,500 & 0,750 \\
CMD14 & 0,754 & 0,860 & 0,244 & 0,884 & 0,272 & 0,125 \\
\hline CMD15 & 0,500 & 0,449 & 0,509 & 0,579 & 0,472 & 0,000 \\
CMD16 & 0,646 & 0,664 & 0,631 & 0,727 & 0,387 & 0,125 \\
\hline CMD17 & 0,772 & 0,655 & 0,393 & 0,617 & 0,480 & 0,333 \\
CMD18 & 0,832 & 0,009 & 0,471 & 0,460 & 0,481 & 0,000 \\
\hline CMD19 & 0,518 & 0,449 & 0,644 & 0,653 & 0,527 & 0,500 \\
CMD20 & 0,832 & 0,614 & 0,631 & 0,700 & 0,223 & 0,500 \\
\hline CMD21 & 0,733 & 0,377 & 0,485 & 0,675 & 0,614 & 0,750 \\
CMD22 & 0,665 & 0,835 & 0,454 & 0,657 & 0,671 & 0,083 \\
\hline CMD23 & 0,794 & 0,699 & 0,472 & 0,531 & 0,391 & 0,500 \\
CMD24 & 0,771 & 0,493 & 0,758 & 0,476 & 0,692 & 0,083 \\
\hline CMD25 & 0,776 & 0,621 & 0,771 & 0,447 & 0,481 & 0,083 \\
CMD26 & 0,731 & 0,735 & 0,471 & 0,651 & 0,235 & 0,125 \\
\hline CMD27 & 0,596 & 0,514 & 0,562 & 0,525 & 0,480 & 0,000 \\
CMD28 & 0,945 & 0,273 & 0,445 & 0,817 & 0,681 & 0,083 \\
\hline CMD29 & 0,562 & 0,694 & 0,721 & 0,810 & 0,235 & 0,500 \\
CMD30 & 0,871 & 0,871 & 0,454 & 0,864 & 0,173 & 0,083 \\
\hline CMD31 & 0,905 & 0,222 & 0,658 & 0,429 & 0,397 & 0,083 \\
CMD32 & 0,926 & 0,173 & 0,017 & 0,285 & 0,347 & 0,125 \\
\hline CMD33 & 0,701 & 0,760 & 0,531 & 0,739 & 0,387 & 0,083 \\
CMD34 & 0,691 & 0,601 & 0,917 & 0,708 & 0,750 & 0,083 \\
\hline CMD35 & 0,622 & 0,706 & 0,543 & 0,655 & 0,485 & 0,750 \\
CMD36 & 0,585 & 0,735 & 0,518 & 0,652 & 0,671 & 0,000 \\
\hline CMD37 & 0,855 & 0,836 & 0,847 & 0,806 & 0,485 & 0,500 \\
\hline & 0,625 & 0,409 & 0,011 & 0,346 & 0,837 & 0,083 \\
\hline 0,574 & 0,671 & 0,464 & 0,602 & 0,527 & 0,125 \\
\hline CMD39 & 0,655 & 0,035 & 0,845 & 0,560 & 0,272 & 0,000 \\
\hline & & & & & &
\end{tabular}

Reorganizing the items based on the different factors comprising the moral disengagement mechanisms they belong to, the following values are obtained:

\begin{tabular}{|c|c|c|c|c|c|}
\hline & Public & Private & & Public & Private \\
\hline \multicolumn{3}{|c|}{ Moral justification } & \multicolumn{3}{|c|}{ Euphemistic labelling } \\
\hline 16 & 0,618 & 0,775 & 1 & 0,528 & 0,549 \\
\hline 23 & 0,805 & 0,547 & 13 & 0,973 & 0,643 \\
\hline 28 & 0,959 & 0,713 & 17 & 0,720 & 0,567 \\
\hline 30 & 0,920 & 0,825 & 22 & 0,729 & 0,632 \\
\hline 37 & 0,842 & 0,898 & 40 & 0,574 & 0,655 \\
\hline \multicolumn{3}{|c|}{ Displacement of responsibility } & \multicolumn{3}{|c|}{ Dehumanization of victim } \\
\hline 2 & 0,675 & 0,606 & 3 & 0,171 & 0,750 \\
\hline 6 & 0,492 & 0,825 & 9 & 0,351 & 0,679 \\
\hline 20 & 0,738 & 0,769 & 32 & 0,837 & 0,154 \\
\hline 25 & 0,789 & 0,650 & 36 & 0,629 & 0,601 \\
\hline 34 & 0,726 & 0,730 & 39 & 0,589 & 0,586 \\
\hline \multicolumn{3}{|c|}{ Advantageous comparison } & \multicolumn{3}{|c|}{ Diffusion of responsibility } \\
\hline 5 & 0,575 & 0,570 & 7 & 0,603 & 0,596 \\
\hline 15 & 0,499 & 0,561 & 14 & 0,765 & 0,737 \\
\hline 26 & 0,679 & 0,687 & 21 & 0,671 & 0,740 \\
\hline 29 & 0,559 & 0,823 & 27 & 0,565 & 0,524 \\
\hline 35 & 0,681 & 0,659 & 38 & 0,732 & 0,195 \\
\hline \multicolumn{3}{|c|}{ Distortion of consequences } & \multicolumn{3}{|c|}{ Attribution of blame } \\
\hline 8 & 0,586 & 0,815 & 4 & 0,839 & 0,824 \\
\hline 10 & 0,763 & 0,751 & 11 & 0,790 & 0,609 \\
\hline 12 & 0,608 & 0,839 & 18 & 0,781 & 0,579 \\
\hline 19 & 0,504 & 0,640 & 24 & 0,752 & 0,659 \\
\hline 33 & 0,675 & 0,671 & 31 & 0,792 & 0,674 \\
\hline
\end{tabular}

A first analysis has compared the two samples based on of gender stratification (Figure 2). When performing this evaluation, however, it has emerged that no interesting results are obtained
Females

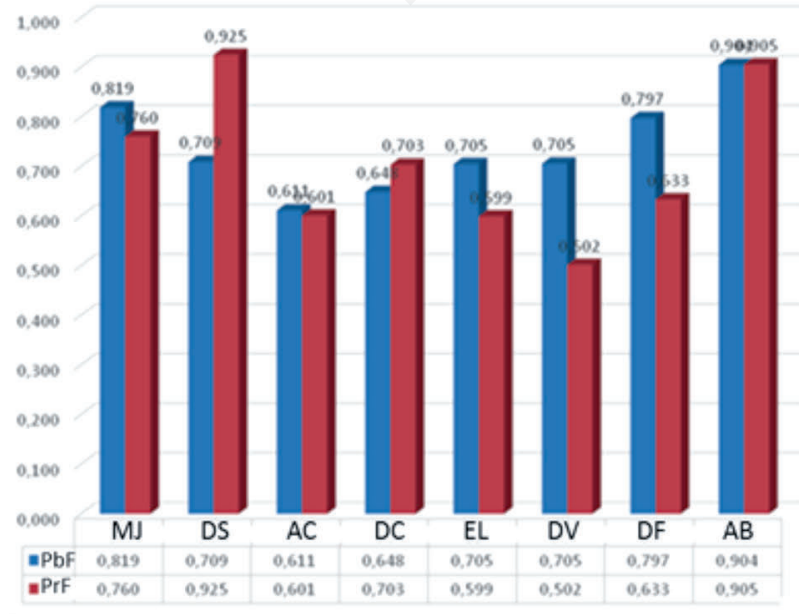

Males

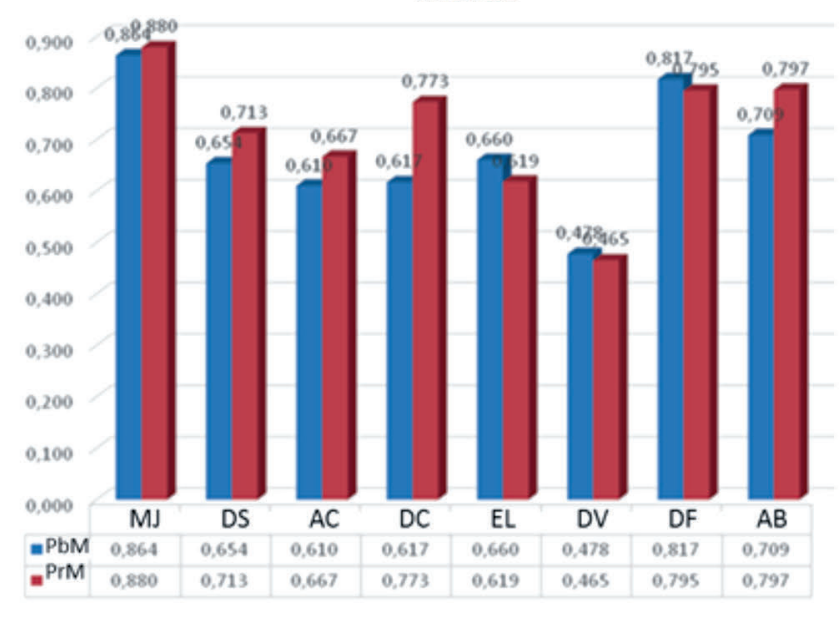

Figure 2. CDM comparison between public and private sectors. 
when comparing the coefficients of the single items, as those values are not sufficient to explain the observed phenomenon. Instead, it is more insightful to apply the least square method to items grouped in the eight mechanisms of moral disengagement.

The analysis of results within the male gender shows a higher level of homogeneity compared to the analysis on the female results. Indeed, very similar attitudes have been observed between public and private sector male employees. Except for the Distortion of Consequences mechanism, which has a higher value among male employees in the private sector, all other mechanisms have comparable values between the two sectors.

Adopting a cross-cutting approach that encompasses all stratifications, i.e. gender and sector, it is possible to analyses the general distribution of the phenomenon, which might actually help distinguishing gender dependent trends and thereafter to look for their eventual causes (Figure 3).

Taking into consideration Moral Justification, there is only a slight difference (between 0.760 and 0.880 ) between male gender employees of public and private sectors. On the contrary, results on female employees in the private sector prove to be significantly inferior both to the male in the same sector and to female in the public sector.

Completely different are the results related to Displacement of Responsibility. In relation to this mechanism, employees of both genders within the public sector show comparable results, as do the male employees of the two sectors, whereas females in the private sector use this mechanism in a higher extent compared to females of the public sector.

The mechanism of Advantageous Comparison is homogeneous throughout the two samples with a very slight variance in the correlation, which is 0.056 higher for male private sector employees.

The private sector, both for female and male gender, seem to rely more on the mechanism of Distortion of Consequences, with male employees making a higher use of this mechanism compared to women. This relation is inverted in the public sector, in which this mechanism is in general less used.

Euphemistic Labelling is more common among public sector employees, in particular among the female gender.

Dehumanization of victim has a particularly high occurrence among the male employees in the public sector, differing for 0.2 percentage points from the average of the other mechanism.
Results show a particularly low value for the mechanism of Diffusion of responsibility among women in the private sector. This value could be interpreted as a greater sense of personal responsibility among them.

In both sectors the female gender recurs to Attribution of Blame with the same high intensity, whereas the male gender adopts this behavior much less. When comparing the results on the Attribution of blame to those on Diffusion of responsibility, the low value of the latter coefficient found among women, which could be interpreted as a high sense of responsibility, acquires a different meaning. The Diffusion of responsibility mechanism, indeed, includes the person's responsibility on the wrong behavior, which is partly alleviated as it is shared with the group. On the contrary, Attribution of Blame takes away all responsibility from the individual, assigning it to external causes. Thus, the combination of these two mechanisms, allow us to conclude that female employees of both sectors have the tendency of blaming others for their misconduct, getting rid of their guilt. Male employees, instead, tend not to shy away from their responsibilities, finding anyway some relief, by sharing them with the group.

The considerations put forward so far need, however, further analysis also to compensate the unbalances between the female and male groups in the sample. Indeed, because of the disproportion of female and male respondents between the two sectors, with the proportion of female respondents being higher in the public sector, it was deemed necessary to discard the gender division, and compare the overall survey results between the public and private sectors.

The comparative analysis of the results displayed in the Figure 4, shows a balanced distribution of the eight mechanisms of moral disengagement between public and private sectors. While public sector employees recur more to Euphemistic Labelling, Dehumanization of victim, Diffusion of responsibility and, Attribution of blame, in the private one they make more use of Moral Justification, Displacement of responsibility, Advantageous comparison and Distortion of consequences.

Except for Dehumanization of victim, which shows a much higher value in the public sector, all values fall almost into the same line between public and private sector, showing a common trend between the two sectors. However, it must be highlighted that the comparison shows that private sector employees, regardless of gender, are keener to activate cognitive processes leading to

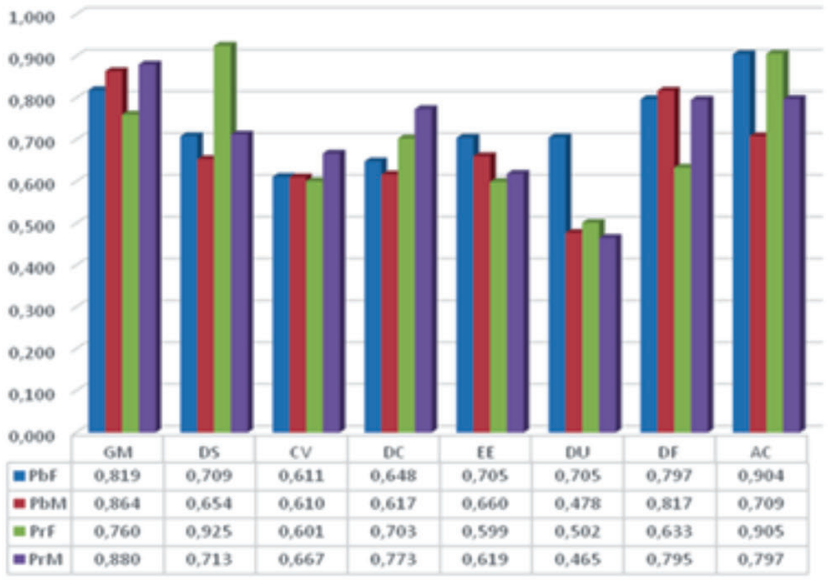

Figure 3. CDM comparison between private and public sector males and females.

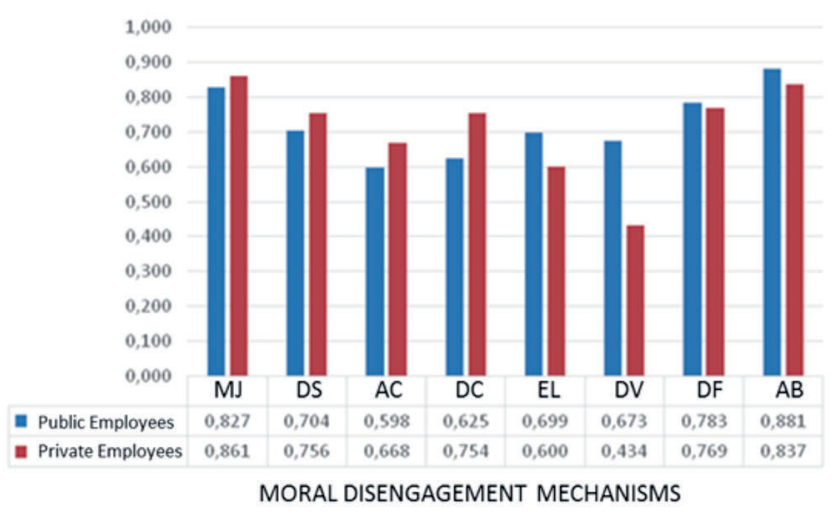

Figure 4. Civic moral disengagement comparison between private and public sector. 
justification of their behavior, without excluding their responsibility, while public service employees tend to hide their misconduct.

Differently from what could be expected, public employees are not prone to adopt moral disengagement mechanisms to justify misbehaviors typically associated to this category. Indeed, the generally accepted idea of the public sector's inefficiency, is not confirmed by a higher predisposition to misconduct of public service employees.

\section{Conclusions}

The results of the Civic Moral Disengagement survey have highlighted how public and private sector employees cannot be distinguished in absolute terms based on whether they recur or not to moral disengagement mechanisms. Rather, the two group of employees can be distinguished on the types of mechanisms they activate.

To answer the questions put forward by the study, it is necessary to understand how the moral disengagement mechanisms impact employees in relation to the peculiarities of public and private work environments

The main difference between public and private occupations lies in the work status that public employees cover and in the responsibilities that follow from it. In the public sector, noncompliance to obligations deriving from work can result in penal and administrative legal repercussions, on top of the disciplinary consequences that can be enforced also in the private sector. For instance, public officials and public service employees can incur into crimes such as embezzlement, corruption and extortion, abuse of office charges, interruption of public services, delay due to negligence etc. These peculiar crimes, some penal and other administrative, put the burden of transgressive conduct directly on the employee, if he is found guilty and if the misconduct causes severe damage to the collectively the public organization is serving.

In this context, the public service employee, following the principles of his occupation, builds his professional self-embracing the moral and legal rules that characterize the role he covers. Aware that he is personally liable for his harmful behavior, this type of employee will not be able to alleviate his misconduct simply justifying it. Justification, indeed, will not discharge the employee from his personal responsibility and thus will not selectively neutralize the mechanisms of self-regulation derived from socialization and from the definition of the professional self. The public employee will be able to overcome the deterrence of an external punishment and the moral condemnation caused by the awareness of having betrayed the relationship of trust underpinning the public occupation only by transferring the reasons of his or her misbehavior outside from his or her responsibility (Diffusion of responsibility Attribution of blame and Displacement of responsibility), or distorting the misconduct so to make it appear legitimate (Euphemistic Labelling and Dehumanization of victim).

The public service employee is somehow subordinate to everyone and no one. On one hand, his or her lability and professional duties spread to all the stakeholders of the public organization in which he operates. On the other hand, he is subject to the control of people such as supervisors, independent monitoring organizations and the public administration itself, which do not have a direct personal economic interest connected to the efficiency and effectiveness of employees, but rather an indirect interest connected to their responsibility in the role of elected monitoring bodies.

On the contrary, the private sector employee has a closer relation with his or her employer. The employer, indeed, leads an organization that aims, according to the company's mission, to the maximization of profits or that in any case has strictly economical purpose and in which the company's success is linked to employees' productivity. According to this logic, the main employee's necessity is making sure that he or she is never perceived as a hindrance to the pursuit of the company's goals. This is because this occurrence could put an end to the relation between employer and employee and the end of the work contract itself, while instead justifying a misconduct (Moral Justification and Advantageous comparison), or making it appear as not strictly attributable to the employee (Distortion of consequences and Displacement of responsibility), would allow preserving the work relation.

Assuming that, when they were hired, the psychological state of employees of both sectors was the same and positive, as obtaining a job satisfies a need that everybody has, the causes that determine single individuals to develop different attitudes and adopt different moral disengagement mechanisms must be enquired. It seems reasonable to attribute these differences, not to a natural predisposition of single employees, but rather to the impact the work environment has on individuals' and the deviant behavior they might adopt. What emerges, thus, is that inefficiency deriving from deviances are determined from the characteristics of work relations rather than from intrinsic employees' features.

It can be noted that the private sector employees' relation with employers is based on the economic interests of both parties, and that the conduct of individuals is limited to the behaviors shared across the group. The risk of being isolated from the rest of the group due to a non-conformed conduct, exposes the private sector employee's misconduct. This risk acts as a deterrent against deviance, as the employee will take it into consideration when evaluating the potential adoption of misconducts through a costbenefit analysis. The possibility of sharing the responsibility on deviance with other group members selectively deactivates the personal self-regulatory system, allowing the individual to overcome the self-blame that is caused by the breaking of moral and disciplinary rules and making thus this risk acceptable (Theory of Social Control, T. Hirschi, 1969). However, the deterrence of an external sanction of contractual nature further limits the possibility of misbehaving.

Work relationships in the public sector are the opposite of this situation. The public service employee cannot find relief, as previously mentioned, in sharing responsibility within the group, as the single individual is liable for his personal misconduct, due to the specific nature of administrative and legal penalties he is subject to. To be able to overcome the sense of guilt and accept the risk deriving from the external penalties, the public service employee has to justify his misconduct by making it appear less severe, so not to be subject to the legal consequences foreseen by the norm governing the occupation, nor to be blocked by the moral inhibitions deriving from the values acquired in the socialization process.

Once again, the Social Cognitive Theory developed by Bandura, stating that individuals adapt to the social environment in which they are inserted according to the concept of 'agency', can be applied. It can be concluded that the selective activation of moral disengagement mechanisms derives from the creation of cognitive processes strongly related to the work environment. This would explain why employees from the two different sectors appear so different, to the point of being considered as two different social categories, belonging to two different groups.

What causes this strong difference between these two categories, thus building the strongly rooted stereotype of the public service employee? We cannot establish a unique reason to this social construct, rather, a plurality of motivations for the diffusion of this stereotype must be looked for. 
First, the research will take into consideration the Theory of Social Identity (H. Tajfel, 1999) and will then juxtapose it to the dichotomic ingroup - outgroup process deriving from the social comparison which induces individuals to express preference towards the group they belong to. The difference perceived by the whole group of public sector employees towards private sector employees and vice versa generates the activation of comparison mechanisms, from which a reciprocal categorization emerges. The private workforce, including also non-employed or retired individuals, represents the main part of society and would perceive the social group it belongs to as better, more busy and productive and subject to "social discrimination" in relation to the public workforce, perceived as composed by privileged individuals, holding undeserved rights and protected in a disproportioned manner compared to the private workforce.

On the contrary, the public workforce will see itself as the victim of a system that does not value excellence and is less meritocratic than the private sector. They would thus feel undervalued despite the high responsibility they face and the exposure to the collective critics based on general unawareness of the objective and subjective situation that public service employees face.

The prevalence of the private sector's perspective over the public sector's one can be easily explained by the numerical relation between the two groups. However, a second explanation should be considered. The public-sector employee relates with the whole group of citizens, who would thus be able to form an opinion on the public context and share it across their social group. By contrast, public workers do not have elements to evaluate the work quality and the amount of work carried out by employees within private companies through a direct experience. This goes also for private sector employees, who cannot evaluate by direct experience the work situation of employees working for different employers. Consequently, the deviance and inefficiency that could take place in private firms are closed within the company's perimeter. We can thus conclude that a first cause of the prevailing negative opinion on public administration can be attributed to the establishment of two distinct social identities, who, by observing and comparing each other, give rise to stereotypical categorization dynamics.

A less absolutistic approach towards the emerging of the stereotype of the public service employee should be however adopted. If such a bad image of public service has spread, to the point that efficient public service employees are perceived as an exception within their category, there must have been an objective deviance from their side, that could be noted and analyzed. It is indeed known, that the main criticism moved against the public administration, beside those relating to political system's inefficiencies, are directed to the malfunctioning of the bureaucratic system, involving negligent, lazy employees not keen on assuming responsibilities and with low problem-solving skills etc.

It could seem that the public administration is ignoring the possibility of recurring to methodologies such as organizational empowerment, that lies at the base of organizational welfare models, that proved to be so performing in private organizations. Even this approach could however be unprecise. In the last decade, indeed, the government and the legislative bodies have enacted numerous initiatives to elevate the general standard quality of public work. For instance, the directive on organizational welfare was enacted on 24/03/2004 by the Public Function Minister, Luigi Mazzella. This was a strategic tool that should have taken public administration in a new era of human resource management, fully embracing the principles of empowerment, adapted to the peculiarities of public organizations, in which work contracts are less discretional and stricter limitations on employee equal treatment apply compared to the private sector.
This directive should be acknowledged from having brought about revolutionary concepts within public organization, compared to the old fashioned hierarchical model that had characterized relationships within public organization until then. Besides this directive, the actions aimed at enhancing performance management processes within public organizations should be mentioned. The first one has been the legislative decree n. 286 of July the $30^{\text {th }} 1999$, named as "Reorganization and enhancement of the monitoring and the cost evaluation tools, and of public administrations' performance and results, according to the $11^{\text {th }}$ article of the law n. 59 of March $15^{\text {th }} 1997^{\prime}$. This then was combined with the legislative decree $n$. 150 of October $27^{\text {th }} 2009$, which introduced the concept of public administration performance, indicating the phases comprising a performance cycle and defining the mechanisms to be adopted to measure, manage and evaluate public administration performance. And still, despite this normative effort, it seems that the empowering attempt and the goal of breaking down the stereotype of the inefficient public service employee have not been met.

A strong prejudice remains and prevents from defining the public administration as resilient with respect to the criticisms it receives. Rather, this phenomenon and the condemnation of the public administration has grown during the past few years, due to some cases of public administration crimes and offences that have caught media and public attention such as examples of favoritisms and corruption, paid absences, fake sicknesses, exportation of relatives' invalidity etc.

What emerges is an image of a public administration who is not capable of proper self-governance. If well written norms have been enacted, but did not provide the expected results, the issue seem to lie within the enforcement of these rules, in other words, in the regulations' actual effectiveness on employees, both in terms of formal punishments deterring deviance and in terms of performance management motivating employees on a psychological level.

It must be taken into consideration that, while some crimes and offences are isolated cases carried out by individuals who have embarked on a deviant path, persisting in misconduct so to make it part of their habits and transforming the professional self, the majority of employees undertakes harmful behavior, which, according to the Theory of Planned Behavior (Ajzen, 1988), is mediated by intentions, and caused by the attitude towards the environment, from subjective norms and from the perception of control.

An uninspiring work environment, where expectations are not met and performance is not rewarded can trigger employee dissatisfaction and frustration. Those conditions are known to be the root causes of deviance, intended as a form of aggressiveness towards the social context, and lead to carrying out harmful behavior and adopting moral disengagement mechanisms to justify it and steering responsibility away. The wider the gap between employees' expectations and their perceived condition and the stronger the resignation and mistrust lowering employees' selfesteem, the more evident their deviance. Consider for example the disappointment and sense of betrayal that could be felt by an employee who is denied the promotion he or she expected and sees other less deserving colleagues being promoted. These subjective psychological conditions act on employees' self-perceptions as group members, leading the individual to dissociate from group objective through self-isolation, resistance to process change, scarce productivity and in general hostility against the whole work environment.

This phenomenon is so widespread in organizations that, because of the frequent and close relations between public service employees and the wide group of public administrations' stakeholders, it is easily visible by a large group of people, thus 
contributing to the stereotype of the inefficient bureaucracy employee.

If we assume that, the motivational boost that employees experience when they are hired, because of the effect of satisfying the need for an occupation, could also be perceived after being promoted, not receiving the expected promotion would activate opposite feelings such as demotivation and frustration, which, as previously mentioned, have a negative impact on the sense of belonging to the group and on the active participation in the pursuit of collective goals.

In these circumstances, the employee can either develop a resilient attitude and analyze his or her working path, trying to create new opportunities to reach his or her objectives, or passively endure the adverse situation, causing a main drop of self-esteem. In the latter case, the individual would have to alleviate his affliction and recover the trust in his personal skills, by translating the responsibility of the misconduct outside himself. Blaming third parties and the employer for personal failure allows recovering selfesteem. However, it causes a sense of resentment towards the employer and the whole work environment, perceived as responsible for the employee's psychological pain. This, in turn, would generate an attitude of resentment and anger, which is expressed as resistance to change, negative reactions to work stimuli and most of all limiting work effort to the bare necessity.

This phenomenon, that at first could mistakenly be confused with Burnout (Freudenberger and Richelson, 1980), can be distinguished by its different root-causes. Burnout emerges from stressful work environments and is typical of the so called "Helping Professions", characterized by strong interpersonal relations. This phenomenon is caused instead by the cognitive dissonance that originates from the divide between the perceived self and the real self. When individuals blame third parties for personal failures, they react to what they perceived as an offence (which could not be real) by trying to highlight how the negative choices of the organization impacted their performance. They could then isolate themselves from others, suddenly reducing their helpfulness towards colleagues, reacting aggressively to observations and rejecting any surplus work activity, to demonstrate that they were subject to a wrong evaluation. Eventually, individuals, hostile to a work environment from which they want to dissociate themselves, resisting the stimuli of dynamic work places, would lose motivation and feel excluded by the group, becoming difficult to predict and hard to manage. This phenomenon is widespread and highly damaging to work places and work activities, as it forces organizations to adopt illogic strategies, such as making employees work overtime to compensate for non- performing individuals.

It is easy to assume that this phenomenon has always existed. However, in the past, it could have been contained through new recruitments and through reward strategies that favor employees provide for their colleagues' inefficiency. Nowadays, the cost cutting efforts within the public administration and the economic crises burdening on private firms have curbed the rewards management strategies and hampered recruiting in both sectors, thus making this phenomenon a relevant organizational issue.

Through isolation, the employee builds a personal perimeter, within which he closes himself or herself and defends his or her position, reacting against anyone who would try to overpass the defined limits, to communicate his or her discomfort. These circumstances can explain the emergence of the stereotype of the inefficient public service employee and the resentment towards the bad management of public human resources which allows inefficient employees to maintain their job.

To understand how such a behavioral model is adopted and perceived as "normal", it is useful to deepen the analysis of the phenomenon in relation to its impact on social relations within the work group and with external individuals (the public organization's users), so to evaluate if recurring and systematic features emerge, giving rise to a psycho-social phenomenon.

Employees' conduct within public organizations represents a key element for the pursuit of organizational goals, according to the principles of the well managed organization, based on efficiency and effectiveness. Improving the common image of Public Administration is not to be intended as the primary objective, but rather as a result of the overcoming of public organizations' limitations and problems. To solve these difficulties, organizations could adopt The Empowerment model and act on the three levels it is articulated in, whose detailed analysis, based on the dimension described in the research model, should be the topic for further study.

Once having determined the tools related to Empowerment mechanisms, and having understood that those are made ineffective by normative constraints, the necessity of a normative alignment that finds a balance between the public cost cutting and personnel governance strategies is evident.

The tools, envisaged by laws, need to be revived, by adopting new personnel cost cutting strategies, that are not limited on blocking recruitment and curbing incentive mechanisms, but rather at moving public administrations towards organizational empowerment. This could be done by encouraging the organization to reach predetermined collective performance targets, that, when reached, allow being entitled to higher expenditure levels. This approach could allow to combine the collective interest in improving organizations' and individuals' performance with the subjective interest of employees in better work conditions, in terms both of fair retribution of their effort, and of a workforce increase, with consequent reduction of individual workload.

Looking at the individual psychological dimension, instead, it is essential to intervene in containing deviance that arises from demotivation and loss of the sense of belonging to the group. There is no doubt that the negative impact of deviant conduct on organizations has economic repercussions, due to higher functioning costs and less efficiency. The described phenomenon would require further analysis aimed at defining its development stages from a social-psychological perspective, in line with the mobbing staged development model developed by Ege (1997). Once the phenomenon has been detailed in all its features in a theoretical perspective, it should be integrated in the group of civil norms that regulate the relationship emerging from job contracts.

It must be mentioned, that the proposed theoretical approach has been developed based on the analysis of survey results from a very limited geographical area. Even though it can be assumed that research results could be representative of the whole nation, further research with wider and more representative sample should be carried out, so to confirm the theoretical model developed by this research.

The last aspect worth to mention consists in the social-political dimension of the Empowerment model. A well working society values the sense of belonging of individuals to the group and consequently activates a virtuous cycle in which individuals are proud to be part of the group, dedicate their best efforts and participate group's results as if they were a reflection of their personal achievements. For organizations to move towards this state, it is necessary to adopt strategies that reward individual skills and competences and as well as organizational structures that allow information sharing and individual participation in decisions, so to enhance employees' 'ingroup' feeling. This requires an increase in the general awareness of new organizational paradigms among organizational leadership, that would compel public organizations' 
leaders to move away from traditional hierarchical organizational systems, based on top down decision making, and embrace better performing models based on participation and meaningful discussion that make organizations Empowered.

\section{References}

Bandura A. (2000). Autoefficacia. Teoria e applicazioni. Erickson. Banzecri J. (1992). Corrispondence analysis handbook. New York: Marcel Dekker.

Caprara GV. (2006). La misura del disimpegno morale nel contesto delle trasgressioni dell'agire quotidiano. Giornale Italiano di Psicologia, 1. Doi:10.1421/21961

Caprara GV. (1996). Assessment of moral disengagement in children. J Personal Social Psychol 71:364-374.

Freudenberger H, Richelson G. (1980). Burnout: the high cost of high achievement. Bantam Books: 1980.
Maslow AH. (2010). Motivazione e personalità. Roma: Armando Editore.

Maton K. (1995). Organizational characteristics of empowering community settings: a multiple case study approach (23 ed.). Am J Comm Psychol.

Hogg MA. (1995). A tale of two theories: a critical comparison of identity theory with social identity theory. Tratto da: da www.campus.fsu.edu: 9/30/2011. https://campus.fsu.edu/bbcswebdav/institution/academic/socia 1 sciences/sociology/reading $\% 20$ lists/social $\% 20$ psych $\% 20$ pre lim\%20readings/iii.\%20self\%20and\%20identity/1995\%20hog g\%20et\%20al\%20-\%20tale\%20of\%20two\%20theories.pdf

Myers DG. (2013). Psicologia sociale (2 ed.). Mc Graw Hill.

Tajfel H. (1999). Gruppi umani e categorie sociali. Bologna: Mulino.

Zimbardo PG. (2006). On rethinking the psychology of tyranny: the BBC. Doi:10.1348/014466605 $\times 81720$

Zimmerman MA. (2000). Empowerment theory. New York: Plenus Publisher.

Correspondence: Maurizio Zorzetto.

E-mail: maurizio.zorzetto@tim.it

Key words: Civic moral disengagement, survey, social cognitive theory, empowerment, theory of reasoned action, theory of planned behavior, behavior, organizational wellbeing.

Parole chiave: Disimpegno morale civico, indagine, teoria sociocognitiva, empowerment, teoria dell'azione ragionata, teoria del comportamento pianificato, comportamento, benessere organizzativo. Palabras clave: Desenganche moral cívico, encuesta, teoría cognitiva social, empoderamiento, teoría de la acción razonada, teoría del comportamiento planificado, comportamiento, bienestar organizacional.

Received for publication: 14 September 2017.

Revision received: 27 December 2017.

Accepted for publication: 19 April 2018.

This article is distributed under the terms of the Creative Commons Attribution Noncommercial License (by-nc 4.0) which permits any noncommercial use, distribution, and reproduction in any medium, provided the original author(s) and source are credited.

(C) Copyright M. Zorzetto, 2018

Licensee PAGEPress, Italy

Rivista di Psicopatologia Forense, Medicina Legale, Criminologia

2018; $23: 27$

doi:10.4081/psyco.2018.27 